\title{
Soybean Peptides Induce Apoptosis in HeLa Cells by Increasing Oxidative Stress
}

\author{
Ho Joong Sung ${ }^{1,2,}$, Yu Jin Jeong ${ }^{1, \$}$, Jihyun Kim ${ }^{1,2}$, Eunsun Jung ${ }^{3}$ and Jin Hyun Jun ${ }^{1,2,4, \dagger}$ \\ ${ }^{I}$ Department of Biomedical Laboratory Science, College of Health Science, Eulji University, \\ Gyeonggi-do 461-713, Korea \\ ${ }^{2}$ Department of Senior Healthcare, BK21 Plus Program, Graduated School, Eulji University, \\ Gyeonggi-do 461-713, Korea \\ ${ }^{3}$ Biospectrum Life Science Institute, Gyeonggi-do 462-807, Korea \\ ${ }^{4}$ Eulji Medi-Bio Research Institute (EMBRI), Eulji University, Gyeonggi-do 461-713, Korea
}

\begin{abstract}
Soy proteins have been extensively studied because of its multiple health benefits. However, the effects of soy proteins on human cervical cancer cells are still unclear. Therefore, this study investigated the effects of soy proteins on HeLa cells and human fibroblasts by using soybean peptides (SPs). SPs selectively increased the generation of reactive oxygen species and apoptosis in HeLa cells but not in fibroblasts. In addition, SPs suppressed the migration of HeLa cells. Although the molecular mechanisms underlying the effects of SPs on human cervical cancer cells need to be investigated further, our findings provide insights on the therapeutic effects of soy protein on cervical cancer.
\end{abstract}

Key Words: Soybean peptides, Reactive oxygen species, Apoptosis, Migration, HeLa cells

\section{INTRODUCTION}

Soy foods are widely consumed for their health benefits (Istfan et al., 1983; Tham et al., 1998). Moreover, soy foods have gained considerable attention in Asia as well as in the Western hemisphere because of their protective effects against cardiovascular diseases and cancer (Food and Drug Administration, 1999). Several studies have shown that soy reduces the concentration of low-density lipoprotein (LDL) cholesterol and total cholesterol, which are the major causative factors of cardiovascular diseases in humans and

*Received: May 14, 2015 / Revised: June 7, 2015

Accepted: June 22, 2015

$\S$ These authors contributed equally to this work

†Corresponding author: Jin Hyun Jun. Department of Biomedical Laboratory Science, College of Health Science, Eulji University Seongnam, Gyeonggi-do 461-713, Korea.

Tel: +82-31-740-7476, Fax: +82-31-740-7354

e-mail: junjh55@eulji.ac.kr

(C) The Korean Society for Biomedical Laboratory Sciences. All rights reserved. animals (Kirk et al., 1998; Zhuo et al., 2004). In addition, soy prevents the conversion of LDL to oxidized LDL, which is implicated in the formation of foam cells during the development of atherosclerosis (Wiseman et al., 2000). Further, soy protects fibroblasts from ultraviolet light- and hydrogen peroxide-induced damage (Yoshikoshi et al., 1996; Kim et al., 2004). Consumption of high levels of soy is correlated with a decreased risk of different cancers (Omoni and Aluko, 2005). Previous studies have suggested that soy exerts antioxidants effects, which attenuate lipid peroxidation and oxidative DNA damage (Wiseman et al., 2000; Djuric et al., 2001). Furthermore, soy protein reduces the production of reactive oxygen species (ROS) in endothelial cells (Mahn et al., 2005). ROS enhance oxidative stress and oxidative DNA damage, which are implicated in inflammation and development of cancer (Sung et al., 2010). Soy also exerts anticancer effects by inducing phase II enzymes such as glutathione S-transferase and quinone reductase, which are involved in the prevention of cancer 
(Appelt and Reicks, 1999). Consistently, an epidemiological study showed that consumption of high levels of soy decreased the occurrence of prostate cancer (Jacobsen et al., 1998).

Besides exerting antiatherogenic and anticancer effects, soy induces the regeneration of damaged nerve cells and promotes wound healing in human fibroblasts (Nizamutdinova et al., 2009; Ma et al., 2010). Healing of the damaged skin is suggested to be optimal for perfect regeneration (Martin, 1997). However, the healing process is complex, and the underlying mechanisms vary from one cell type to another. Cell migration, one of the several processes involved in wound healing, is also different between non-cancer and cancer cells. In epidermal cells, cell migration is essential for re-epithelialization (Clark et al., 1982), which is a desirable process. However, enhanced cell migration during cancer development is a cause of concern, especially during angiogenesis and metastasis (Coussens and Werb, 2002). Although multiple studies have reported various effects of soy protein on different cells, the effects of soy protein on human cervical cancer cells remain unclear. Therefore, we investigated the effects of soy protein on HeLa cells and human fibroblasts by using soybean extracts (SPs). We observed that SPs increased oxidative stress and apoptosis in and suppressed the migration of HeLa cells.

\section{MATERIALS AND METHODS}

\section{Materials}

Human cervical cancer cells (HeLa) and human fibroblasts were obtained from ATCC (Manassas, VA, USA) and Lonza (Normal, IL, USA), respectively. SPs (Glycine max var.) were prepared as described previously (Lee et al., 2012) and were kindly provided by Biospectrum Life Science Institute (Gyeonggi, Korea). Dulbecco's modified Eagle's medium (DMEM), fetal bovine serum (FBS), penicillin/streptomycin, and 5,6-chloromethyl-2,7-dichlorodihydrofluorescein diacetate (CM-H2DCFDA, DCF) were purchased from Life Technologies Corporation (Carlsbad, CA, USA). Alexa 594conjugated anti-rabbit antibody and 3-(4,5-dimethylthiazol2-yl)-2,5-diphenyltetrazolium bromide (MTT) were purchased from Sigma-Aldrich (St. Louis, MO, USA). TUNEL assay kits were obtained from Promega (Madison, WI, USA).

\section{Cell cultures}

HeLa cells and human fibroblasts were maintained in DMEM supplemented with $10 \%$ FBS and $1 \%$ penicillin/ streptomycin in a tissue culture incubator, unless otherwise indicated.

\section{Cell viability tests}

Cell viability was determined by performing MTT assay. Briefly, $1 \times 10^{4}$ cells were plated in 96-well plates a day before SP treatment. After SP treatment, the cells were grown for $24 \mathrm{~h}$. Next, $20 \mu \mathrm{l}$ of $5 \mathrm{mg} / \mathrm{ml}$ MTT solution in PBS and $100 \mu \mathrm{l}$ of DMSO were added to each well to dissolve formazan crystals. Absorbance was measured at $540 \mathrm{~nm}$ by using a plate reader (Bio-Rad Laboratories Ltd., Hercules, CA, USA).

\section{ROS measurement}

ROS measurements were performed as reported previously (Kim et al., 2012). Briefly, the cells were plated at equal densities in 96-well plates a day before SP treatment. After SP treatment, the cells were incubated with $5 \mu \mathrm{M}$ DCF for $30 \mathrm{~min}$ in a tissue culture incubator and were washed twice with pre-warmed PBS. A 96-well plate fluorescence reader (Anthos Labtech, Salzburg, Austria) was used to quantify DCF fluorescence signals.

\section{TUNEL assay}

Apoptosis was determined by performing TUNEL assay according to the manufacturer's protocol. Images of apoptotic cells were obtained using an inverted fluorescence microscope (Carl Zeiss, Jena, Germany) and were analyzed using i-Solution software (IMT i-Solution, Vancouver, BC, Canada).

\section{Wound healing assay}

The cells were plated at equal densities in 6-well plates and were grown up to $90 \sim 100 \%$ confluence. The cell layer was scratched using a P-200 pipette tip. After SP treatment, the cells were photographed at 0 and $24 \mathrm{~h}$ by using an inverted microscope equipped with AxioCam software 
(A)

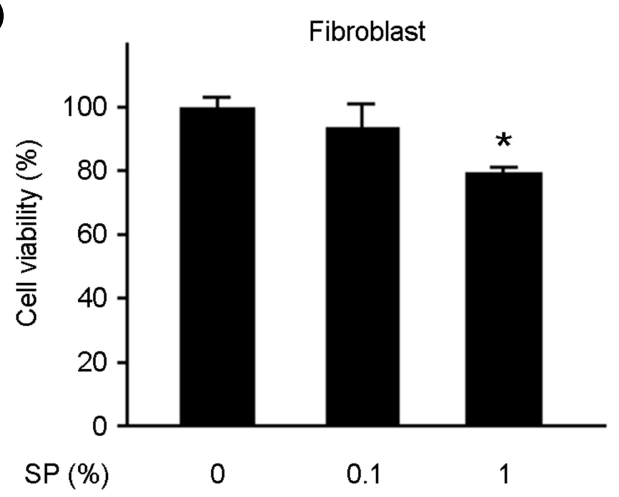

B

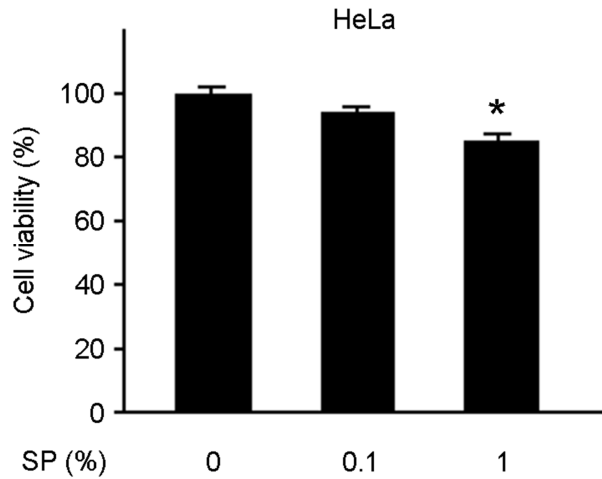

Fig. 1. Effects of SPs on cell viabilities. Equal densities $\left(1 \times 10^{4}\right)$ of human fibroblasts $(\mathrm{A})$ and HeLa cells $(\mathrm{B})$ were incubated in 96 -well plates containing DMEM supplemented with $1 \%$ FBS and $0.1 \%$ or $1 \%$ SPs for $24 \mathrm{~h}$. Cell viabilities were measured by performing the MTT assay $(\mathrm{n}=3)$. $P$-values $\left({ }^{*} P<0.05\right)$ were determined using Student's $t$-test, and the values are expressed as mean \pm SEM.

A

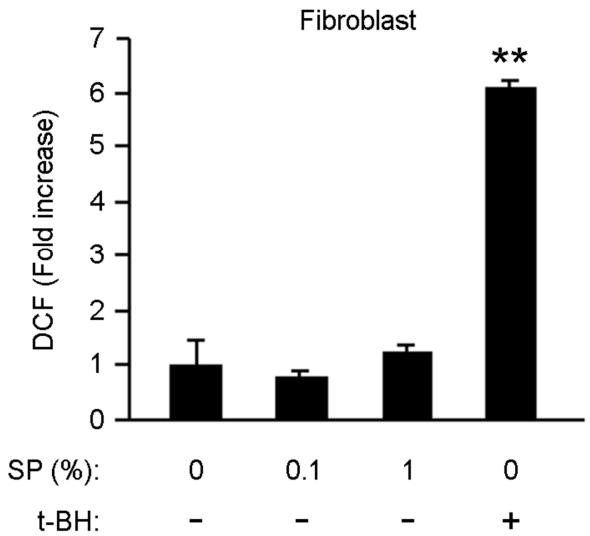

C

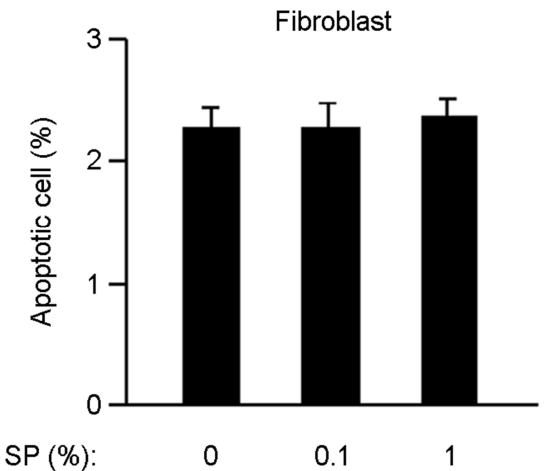

B

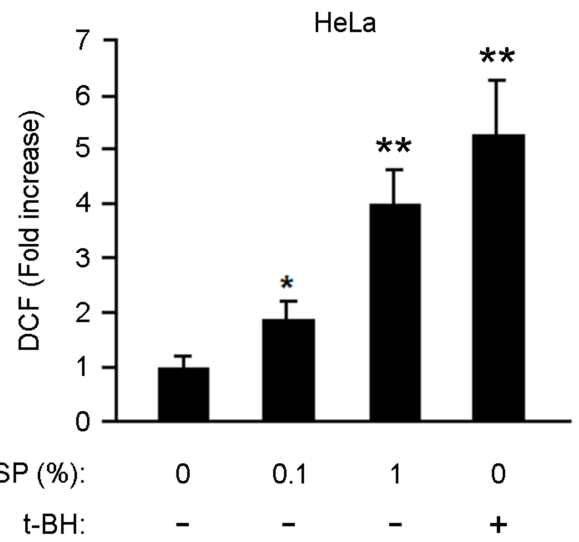

D

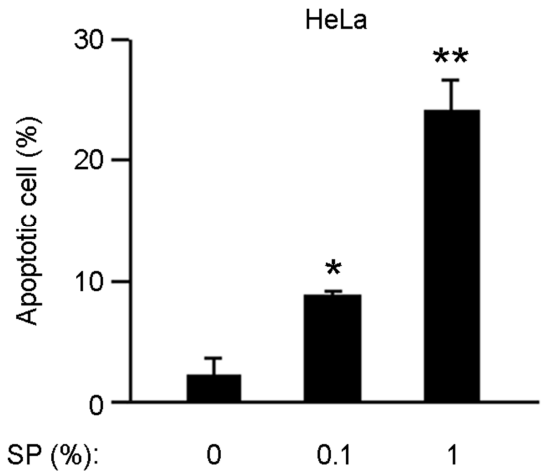

Fig. 2. SPs increase ROS generation and induce apoptosis in HeLa cells. Human fibroblasts (A) and HeLa cells (B) were plated in 96-well plates and were incubated with the indicated concentrations of SPs for $24 \mathrm{~h}$, followed by incubation with $400 \mu \mathrm{M}$ tert-butyl hydroxide $(\mathrm{t}-\mathrm{BH})$ for $1 \mathrm{~h}$ as a positive control. After incubation, the cells were treated with $5 \mu \mathrm{M}$ DCF solution for 30 min in a tissue culture incubator, and ROS generation was measured using a 96-well fluorescence plate reader $(n=3)$. ROS generation was quantified in terms of fold increase. Both the cell lines were plated at the same densities on 2-well chamber slides and were incubated with the indicated concentrations of SPs for $24 \mathrm{~h}$ (C and D). The TUNEL assay was performed, and the number of apoptotic cells was quantified and expressed as percentages. $P$-values $\left(* P<0.05,{ }^{*} P<0.01\right)$ were determined using Student's $t$-test, and the values are expressed as mean \pm SEM. 
A

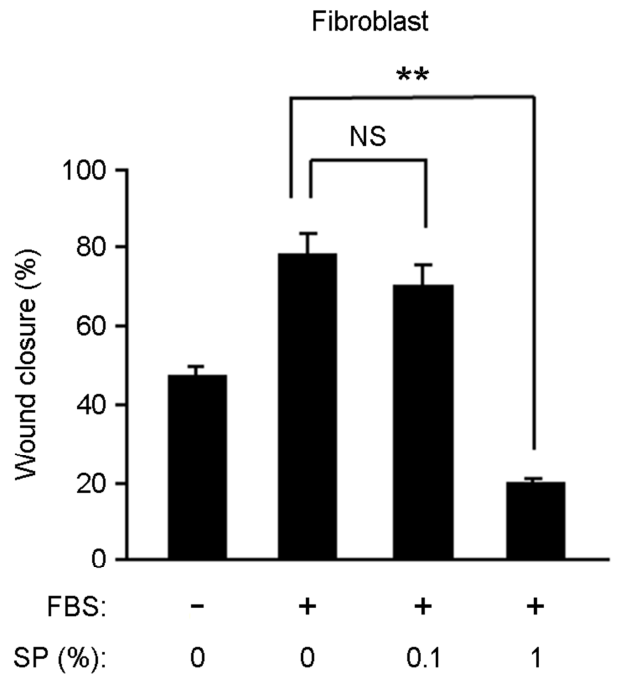

B

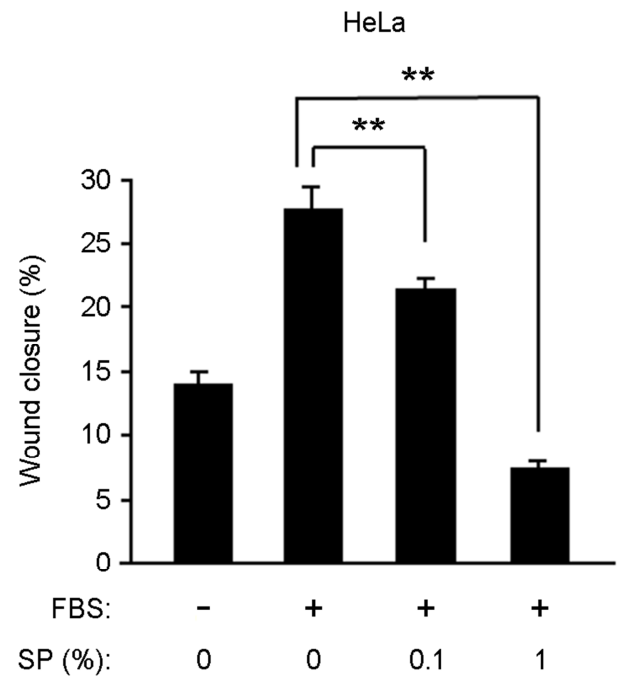

Fig. 3. SPs inhibit the migration of HeLa cells. Cultures of human fibroblasts (A) and HeLa cells (B) were scratched using a P-10 pipette tip and were incubated with the indicated concentrations of SPs for $24 \mathrm{~h}$. Images of the wounds were taken at the time of scratching ( $0 \mathrm{~h})$ and after $24 \mathrm{~h}$. The images were then assessed to determine percentage wound healing $(\mathrm{n}=3)$. $P$-values $(\mathrm{NS}$; not significant, $* * P<0.01)$ were determined using student's $t$-test, and values are expressed as mean \pm SEM.

(Carl Zeiss) and the gap distance of wound healing was measured.

\section{Statistical analysis}

$P$-values were calculated using Student's $t$-test.

\section{RESULTS}

\section{Effects of SPs on the viabilities of HeLa cells and human \\ fibroblasts}

To investigate whether SPs had differential effects on the viabilities of HeLa cells and human fibroblasts, we determined the cytotoxicity of SPs by performing the MTT assay (Fig. 1A and B). Both the cell lines were treated with $0.1 \%$ or $1 \%$ SPs for $24 \mathrm{~h}$. Treatment with $0.1 \% \mathrm{SP}$ did not exert significant cytotoxic effects on both the cell lines. However, treatment with $1 \%$ SP significantly decreased the viabilities of HeLa cells and fibroblasts (16\% and 22\%, respectively).

\section{SPs increase ROS generation and induce apoptosis in HeLa cells}

We investigated the effects of SPs on ROS generation in
HeLa cells and fibroblasts. SPs significantly induced ROS generation in HeLa cells in a dose-dependent manner (Fig. 2B) but did not affect ROS generation in fibroblasts (Fig. $2 \mathrm{~A})$. Based on the reported correlation between ROS generation and apoptosis (Zhang et al., 2008), we examined the apoptosis induced by SP treatment. We observed that SPs significantly increased the number of apoptotic cells in HeLa cells but not in fibroblasts (Fig. 2C and D), which was consistent with the results summarized in Fig. 2B.

\section{SPs suppress the migration of HeLa cells}

Because SPs induced cell death (Fig. 2D), we investigated the effect of SPs on the migration of HeLa cells by performing a wound healing assay. Treatment with $0.1 \% \mathrm{SP}$ significantly inhibited the wound healing in HeLa cell culture (Fig. 3B). However, treatment with 1\% SP suppressed the migration of both the cell lines (Fig. 3).

\section{DISCUSSION}

Several studies have shown that soy, especially isolated soy protein, exerts multiple beneficial effects on the human body (Tham et al., 1998; Omoni and Aluko, 2005). SPs 
induce stem cell proliferation by mediating signal transduction, including activation of ERK and TGF- $\beta 1$ pathways (Lee et al., 2012). Further, SPs exhibit anticancer activity (Saleem, 2009); however, the underlying mechanisms are yet to be determined. A recent study reported that soyderived isoflavone mixtures induced apoptosis in HeLa cells by disrupting mitochondrial membrane potentials (Xiao et al., 2011). Although a previous study reported the cytotoxic effects of soy-derived compounds on HeLa cells, this study did not investigate the cause of cell death. Therefore, we examined the anticancer effects of SPs on HeLa cells by using human fibroblasts as controls. To determine the cytotoxic effects of SPs on HeLa cells, we conducted cell viability assays in a dose-dependent manner (Fig. 1). However, we did not observe any difference in the cytotoxic effects of SPs on both the normal and cancer cell lines. In the present study, we used 2 SP doses with a 10-fold difference in their concentrations. Therefore, further studies should be performed to examine SP doses with smaller differences in their concentrations. Because multiple studies have reported the antioxidant effect of soy on cancer cells (Jacobsen et al., 1998; Appelt and Reicks, 1999), we examined the antioxidant effect of SPs on HeLa cells by measuring of ROS generation (Fig. 2A and B). In contrast to previous studies, we observed that SPs significantly increased ROS generation in HeLa cells even at a non-cytotoxic concentration $(0.1 \% \mathrm{SP})$. In addition, SPs selectively increased ROS generation in HeLa cells in a dose-dependent manner but not in fibroblasts. It is interesting that SPs induced ROS generation only in cancer cells but not in non-cancer cells under the same experimental conditions. As we haven't find the regulatory role of SPs on ROS generation in HeLa cells, the molecular mechanism of ROS generation by SPs treatment should be determined in further studies. Despite the effects of ROS in promoting cancer, such as increasing aggressive phenotype (Kumar et al., 2008), intrinsic ROS stress (i.e., excessive ROS generation) in cancer cells induces apoptosis by releasing cytochrome $\mathrm{c}$ from damaged mitochondrial membranes (Zhang et al., 2008). Soy protein induces apoptosis in breast cancer cells by generating ROS (Ullah et al., 2011). To verify the correlation between ROS generation and cell death, we assessed apoptosis induced by SP treatment. Although ROS enhance oxidative stress and oxidative DNA damage that promote tumorigenesis (Sung et al., 2010), ROS generation by SP treatment significantly increased apoptosis in HeLa cells in the present study (Fig. 2D). This result might be affected by the cytotoxic effects of SPs. However, the nontoxic dose $(0.1 \%)$ of SP also induced apoptosis in HeLa cells. In contrast, no apoptosis was reported in fibroblasts even after treatment with the cytotoxic dose (1\%) of SP, which decreased the viability of these cells (Fig. 1B). This discrepancy might be because of the use of different methods to determine cell viability. The TUNEL assay is highly selective in detecting apoptotic cells but not necrotic cells or cells with DNA strand breaks resulting from drug treatments (Gold et al., 1994). ROS is a key regulator in cell migration (Kim et al., 2012), and ROS generation increases cell migration and invasiveness of primary and cancer cells, respectively (Schroder et al., 2007; Kumar et al., 2008). However, the potential mechanisms involved in ROSinduced cell death may decrease the migration of cancer cells (Pelicano et al., 2004). Therefore, we examined the effect of ROS generation on HeLa cells (Fig. 3B). Although treatment with $1 \%$ SP, which exerted cytotoxic effects on both fibroblasts and HeLa cells (Fig. 1), suppressed the migration of both the cell lines, treatment with $0.1 \% \mathrm{SP}$ only attenuated the migration of HeLa cells. However, the detailed mechanisms underlying this effect should be clarified in further studies. Especially, the effect of SPs in inducing apoptotic and non-apoptotic cell death should be examined. In this study, we observed that SPs increased apoptosis in HeLa cells by generating ROS. Although the molecular mechanisms underlying this effect of SPs need to be determined, our findings may contribute to the understanding of the therapeutic effects of soy on human cervical cancer.

\section{Conflict of interest}

The authors declare that they have no conflicts of interest in the research.

\section{REFERENCES}

Appelt LC, Reicks MM. Soy induces phase II enzymes but does not inhibit dimethylbenz[a]anthracene-induced carcinogenesis 
in female rats. J Nutr. 1999. 129: 1820-1826.

Clark RA, Lanigan JM, DellaPelle P, Manseau E, Dvorak HF, Colvin RB. Fibronectin and fibrin provide a provisional matrix for epidermal cell migration during wound reepithelialization. J Invest Dermatol. 1982. 79: 264-269.

Coussens LM, Werb Z. Inflammation and cancer. Nature. 2002. 420: $860-867$

Djuric Z, Chen G, Doerge DR, Heilbrun LK, Kucuk O. Effect of soy isoflavone supplementation on markers of oxidative stress in men and women. Cancer Lett. 2001. 172: 1-6.

Food and Drug Administration, HHS, Final rule. Food labeling: health claims; soy protein and coronary heart disease. Fed Regist. 1999. 64: 57700-57733.

Gold R, Schmied M, Giegerich G, Breitschopf H, Hartung HP, Toyka KV, Lassmann H. Differentiation beteween cellular apoptosis and necrosis by the combined use of in situ tailing and nick translational techniques. Lab Invest. 1994. 71: 219 -225 .

Istfan N, Murray E, Janghorbani M, Evans WJ, Young VR. The nutritional value of a soy protein concentrate (STAPRO-3200) for long-term protein nutritional maintenance in young men. J Nutr. 1983. 113: 2524-2534.

Jacobsen BK, Knutsen SF, Fraser GE. Does high soy milk intake reduce prostate cancer incidence? The Adventist Health Study (United States). Cancer Causes Control. 1998. 9: 553-557.

Kim SY, Kim SJ, Lee JY, Kim WG, Park WS, Sim YC, Lee SJ. Protective effects of dietary soy isoflavones against UVinduced skin-aging in hairless mouse model. J Am Coll Nutr. 2004. 23: 157-162.

Kim YS, Sull JW, Sung HJ. Suppressing effect of resveratrol on the migration and invasion of human metastatic lung and cervical cancer cells. Mol Biol Rep. 2012. 39: 8709-8716.

Kirk EA, Sutherland P, Wang SA, Chait A, LeBoeuf RC. Dietary isoflavones reduce plasma cholesterol and atherosclerosis in C57BL/6 mice but not LDL receptor-deficient mice. J Nutr. 1998. 128: 954-959.

Kumar B, Koul S, Khandrika L, Meacham RB, Koul HK. Oxidative stress is inherent in prostate cancer cells and is required for aggressive phenotype. Cancer Res. 2008. 68: 1777-1785.

Lee J, Roh KB, Kim SC, Park D. Soy peptide-induced stem cell proliferation: involvement of ERK and TGF-beta1. J Nutr Biochem. 2012. 23: 1341-1351.

Ma TC, Campana A, Lange PS, Lee HH, Banerjee K, Bryson JB, Mahishi L, Alam S, Giger RJ, Barnes S, Morris SM, Jr., Willis DE, Twiss JL, Filbin MT, Ratan RR. A large-scale chemical screen for regulators of the arginase 1 promoter identifies the soy isoflavone daidzeinas a clinically approved small molecule that can promote neuronal protection or regeneration via a cAMP-independent pathway. J Neurosci. 2010. 30: 739-748.

Mahn K, Borras C, Knock GA, Taylor P, Khan IY, Sugden D, Poston L, Ward JP, Sharpe RM, Vina J, Aaronson PI, Mann GE. Dietary soy isoflavone induced increases in antioxidant and eNOS gene expression lead to improved endothelial function and reduced blood pressure in vivo. FASEB J. 2005. 19: 1755-1757.

Martin P. Wound healing--aiming for perfect skin regeneration. Science. 1997. 276: 75-81.

Nizamutdinova IT, Kim YM, Chung JI, Shin SC, Jeong YK, Seo HG, Lee JH, Chang KC, Kim HJ. Anthocyanins from black soybean seed coats stimulate wound healing in fibroblasts and keratinocytes and prevent inflammation in endothelial cells. Food Chem Toxicol. 2009. 47: 2806-2812.

Omoni AO, Aluko RE. Soybean foods and their benefits: potential mechanisms of action. Nutr Rev. 2005. 63: 272-283.

Pelicano H, Carney D, Huang P. ROS stress in cancer cells and therapeutic implications. Drug Resist Updat. 2004. 7: 97-110.

Saleem M. Lupeol, a novel anti-inflammatory and anti-cancer dietary triterpene. Cancer Lett. 2009. 285: 109-115.

Schroder K, Helmcke I, Palfi K, Krause KH, Busse R, Brandes RP. Nox1 mediates basic fibroblast growth factor-induced migration of vascular smooth muscle cells. Arterioscler Thromb Vasc Biol. 2007. 27: 1736-1743.

Sung HJ, Ma W, Wang PY, Hynes J, O'Riordan TC, Combs CA, McCoy JP, Jr., Bunz F, Kang JG, Hwang PM. Mitochondrial respiration protects against oxygen-associated DNA damage. Nat Commun. 2010. 1: 5.

Tham DM, Gardner CD, Haskell WL. Clinical review 97: Potential health benefits of dietary phytoestrogens: a review of the clinical, epidemiological, and mechanistic evidence. J Clin Endocrinol Metab. 1998. 83: 2223-2235.

Ullah MF, Ahmad A, Zubair H, Khan HY, Wang Z, Sarkar FH, Hadi SM. Soy isoflavone genistein induces cell death in breast cancer cells through mobilization of endogenous copper ions and generation of reactive oxygen species. Mol Nutr Food Res. 2011. 55: 553-559.

Wiseman H, O'Reilly JD, Adlercreutz H, Mallet AI, Bowey EA, Rowland IR, Sanders TA. Isoflavone phytoestrogens consumed in soy decrease $\mathrm{F}(2)$-isoprostane concentrations and increase resistance of low-density lipoprotein to oxidation in humans Am J Clin Nutr. 2000. 72: 395-400. 
Xiao J, Huang G, Geng X, Qiu H. Soy-derived isoflavones inhibit hela cell growth by inducing apoptosis. Plant Foods Hum Nutr. 2011. 66: 122-128.

Yoshikoshi M, Yoshiki Y, Okubo K, Seto J, Sasaki Y. Prevention of hydrogen peroxide damage by soybean saponins to mouse fibroblasts. Planta Med. 1996. 62: 252-255.

Zhang R, Humphreys I, Sahu RP, Shi Y, Srivastava SK. In vitro and in vivo induction of apoptosis by capsaicin in pancreatic cancer cells is mediated through ROS generation and mitochondrial death pathway. Apoptosis. 2008. 13: 1465-1478.

Zhuo XG, Melby MK, Watanabe S. Soy isoflavone intake lowers serum LDL cholesterol: a meta-analysis of 8 randomized controlled trials in humans. J Nutr. 2004. 134: 2395-2400. 